Citizenship Education and the Role of Immigrant Students in the Nordic Countries

\title{
Leiviskä, Anniina
}

Springer

2020

Leiviskä , A 2020 , Citizenship Education and the Role of Immigrant Students in the Nordic Countries . in T Strand (ed.), Rethinking Ethical-Political Education . Contemporary

Philosophies and Theories in Education, vol. 16 , Springer , Cham , pp. 121-135 . https://doi.org/10.1007/978-3-030

http://hdl.handle.net/10138/332686

https://doi.org/10.1007/978-3-030-49524-4_8

acceptedVersion

Downloaded from Helda, University of Helsinki institutional repository.

This is an electronic reprint of the original article.

This reprint may differ from the original in pagination and typographic detail.

Please cite the original version. 


\title{
Citizenship education and the role of immigrant students in the Nordic countries
}

\begin{abstract}
This contribution addresses the issue of citizenship education and the role of immigrant students in the Nordic countries from the perspective of liberal theories of citizenship education. Liberal approaches to citizenship education have recently encountered rigorous critique: the critics argue that the supposedly democratic, rational, and neutral principles and ideals associated with liberal democratic theories are in reality rooted in a particular way of life and national identity. Accordingly, inculcating these principles and ideals in citizenship education excludes and marginalizes students belonging to minorities, immigrant students in particular. This contribution aims to respond to this critique by separating between two branches of liberal theory of citizenship education, 'patriotic' and 'political'. The paper argues that while the 'patriotic' approach is vulnerable to the aforementioned critique, it does not apply to the 'political' line of thought. Rather, the 'political' approach, rooted in John Rawls' political liberalism and the notion of reasonableness, provides a foundation for criticizing policies and practices that marginalize students with immigrant backgrounds. Finally, utilizing Rawlsian theory of citizenship education as a starting point, the paper makes some suggestions how the status of immigrant students could be improved in the Nordic countries.
\end{abstract}

Keywords: citizenship education, democracy, political liberalism, patriotism, immigration

\section{Introduction}

As the title of this volume indicates, the essays of this book are dedicated to the endeavor of rethinking ethical-political education in the Nordic context. Such re-thinking is indeed required, as the political climate of the Nordic countries has changed rather drastically during the past decades. We have been witnessing political changes that no-one could have anticipated at the heyday of the Nordic welfare model or the time of the establishment of the European Union: far right populist parties have made their way to the official party map in many Scandinavian countries and xenophobic views are becoming more and more common in everyday political discourse. In the current political climate, the notion of citizenship is often associated with issues of national identity, and questions such as who can be regarded, and who has the right to become, a citizen of a particular nation state, and on what terms. Against this background, the sudden increase in the amount of citizenship education initiatives in the EU-area also raises the question whether they are motivated by a genuine desire to strengthen democratic values or are they rather associated with the concern for the possible deterioration of particular national identities.

Especially in the liberal tradition of philosophy of education, citizenship education has typically been considered as one of the most important functions of public schooling in democratic societies. It has been widely accepted within this tradition that maintaining a stable and just political order under pluralistic conditions requires virtuous democratic citizens who are capable of adhering to common rules of co-operation with other citizens having values and conceptions of the good different from their own (e.g. Callan, 1997; Gutmann, 1999). Moreover, the acquisition of the necessary democratic virtues has been understood as requiring appropriate citizenship education. However, in recent discussions, the liberal democratic idea of citizenship education has been subjected to rigorous critique. It has been argued, among other 
things, that the inculcation of specific ideals, values, and principles associated with democratic citizenship, and fostering obedience to the existing political organization, effectively marginalize and exclude minority groups, especially students with immigrant backgrounds, thus making citizenship education a vehicle of discrimination. One of the arguments presented by critics is that citizenship education masks as 'universal' or 'rational' such values and principles that are in fact rooted in a particular national identity and way of life, and which therefore serve to legitimize the current balance of power in society (e.g. Merry, 2018; Säfström, 2010).

In this paper, I examine two branches of liberal theory, (1) liberal "patriotism" primarily represented by Eamonn Callan (1997) and William Galston (1991), and (2) John Rawls' political liberalism (2005), from the viewpoint of the aforementioned critique. As an example of this critique, I will particularly focus on Carl Anders Säfström's (2011) examination of the role of immigrant students in the Swedish school system. Säfström's central claim is that thinking of democracy in terms of consensus along the lines of liberal theories of democracy is profoundly mistaken, because this consensus in reality reflects a particular ideal of national identity - in this case 'Swedishness' and Swedish way of life - and thus education building upon such consensus marginalizes immigrant students who do not share in this identity.

My argument is that although theories in the liberal tradition of citizenship education typically emphasize the importance of citizens' adherence to common rules of co-operation, the 'political' branch of liberalism that promotes liberal neutrality - or, as Victoria Costa (2009, p. 98) puts it, "principle-based" liberalism - is far less vulnerable to the aforementioned critique than its patriotic alternative. Accordingly, my attempt in this paper is to distinguish between theories in favor of a form of liberal neutrality, Rawls' political liberalism in particular, and those endorsing liberal patriotism as an educational aim. Furthermore, my aim is to demonstrate that the notion of reasonableness, which can be regarded as a central aim of citizenship education in the Rawlsian tradition, is not only in sharp contrast with nationalist values but can also be rationally justified in a liberal, pluralist context. In other words, I suggest that in a society consisting of a multiplicity of different, sometimes even mutually incompatible comprehensive doctrines, reasonableness is a political virtue that cannot be disregarded without jeopardizing the legitimacy and stability of a democratic polity. I thus argue that reasonableness should not be seen an arbitrary or politically determined criterion that can be used to justify nationalist agendas; rather, it is a criterion that can be utilized to assess and criticize such illegitimate practices and policies mentioned by Säfström and others. Finally, I reflect upon the role of immigrant students in the Nordic educational systems and utilize the Rawlsian approach to citizenship education to outline some suggestions how the position of these students could be improved.

\section{The critique of liberal citizenship education}

Citizenship education has been an enduring topic of interest particularly in the liberal tradition of philosophy of education. Especially since the 1990s there has been a vast body of literature examining questions such as, what the role of schools and other educational institutions is in the formation of future citizens of liberal democratic societies, and what the proper aims of citizenship education are or should be. Most liberal theories of citizenship education are motivated by questions of ethical and political pluralism and the accommodation of diversity in liberal democratic societies (e.g. Callan, 1997; Galston, 1991; Gutmann, 1999; Costa 2011; 
Reich, 2008). Accordingly, liberal views of citizenship education generally include some version of the "common school ideal" (e.g. Callan, 1997; Reich, 2008) according to which schools should prepare students for democratic citizenship in a pluralist society. This should be done not only by teaching students the relevant knowledge and skills, but also by providing environments where they learn to cooperate with their peers from different backgrounds. It is thus taken to be a central function of common schools to foster a shared sense of citizenship and mutual respect among students from different backgrounds (Neufeld, 2013).

Lately, however, the idea of liberal citizenship education has been challenged by philosophers of education coming from the so-called 'radical' tradition of democracy. Authors such as Gert Biesta (2009, 2011), Michael Merry (2018), and Carl-Anders Säfström (2010) have associated liberal theories of citizenship education with problematic educational policies and practices in which students in marginalized positions, especially immigrant students, are further marginalized and denied access to meaningful conceptions of citizenship by contrasting their cultural, religious and ethnic backgrounds and identities with desired ideals of liberal citizenship. The primary argument presented by the aforementioned authors is that liberal theories of citizenship education are based on politically determined, ultimately ideological values and premises, which are merely disguised as universal or rational principles associated with democracy and citizenship. According to these authors, the assertion of these values as universal, objective or rational merely serves to legitimize their inculcation in future citizens and, consequently, the marginalization and exclusion of those students who do not share in these values. Especially Merry (2018) and Säfström (2010) suggest that the ideal of liberal citizenship underlying citizenship education initiatives is often associated with a particular view of national identity. It is no accident, Merry (2018) argues, that there has been a plethora of citizenship education initiatives in European democracies after the recent mass-migration; in his view, these initiatives are deeply intertwined with the rise of right-wing populism and nationalist ideologies.

Carl Anders Säsftröm's (2010) contribution is particularly interesting from the Nordic perspective, as he utilizes the example of Swedish national curriculum to discuss the issues mentioned above. According to Säfström, the so-called democratic values promoted in the Swedish national curriculum are in reality rooted in a particular national identity and selfunderstanding. In other words, Säfström claims that when the Swedish school system declares to be fostering liberal democratic values and principles, it actually constructs a certain image of Swedishness as a non-contestable, consensual frame of reference for a democratic way of life. Through the assimilation of democratic core values and national identity, the existing form of schooling legitimizes itself to the extent where it becomes its own rationality and thus needs no external ground to justify its claims (Säfström, 2010). Accordingly, the school system can label as unimportant or nonexistent all voices and forms of otherness that do not belong to the established order. Säfström's argument is that this is exactly what happens to immigrant students within the Swedish school system and through the implication of the Swedish curriculum. The national curriculum, and especially the school subject 'Swedish as a second language', is intended to socialize immigrant students to certain core values associated with Swedishness and the Swedish society. As a consequence, the immigrant has the option of adopting a Swedish identity or having no role or "no name", as Säfström (2010, p. 616) puts it, in the existing order of things. Hence, Säfström concludes that regarding consensus as the symbol of democratic processes and practices risks making citizenship education profoundly undemocratic or even discriminative. 
Similar interpretations have also been made of the educational systems and curricula of other Nordic countries. One of these interpretations is by Simon Laumann Jørgensen (2015) who attempts to demonstrate how nationalist intentions in history teaching have become more and more explicit in the Danish curriculum over the past few years. Jørgensen argues that particularly the newly included 'Canon of Danish History' expresses the idea that, for the sake of social cohesion, it is necessary to provide the next generation with a strong sense of 'Danishness.' According to Jørgensen, the Canon portrays negative historical episodes as consequences of external enemy intrusion while positive ones are marked by internal developments of liberation and progress. He thus suggests that the Canon promotes an overtly positive narrative of Danish history as a progression from peacefulness and justice to an even higher degree of peacefulness, liberality, justice, and modernism through non-violent steps and peaceful revolutions. In Jørgensen's (2015) view, the Canon thus reflects the Danish post-9/11 climate in which "modern protestant Scandinavia" (p. 446) is contrasted particularly with Islamic and Middle Eastern identities in a way that is likely to widen the gap between minority and majority students.

While representing a more cautiously critical reading of Nordic educational policies, Holm and Londen's (2010) study of Finnish multicultural education is somewhat in line with the aforementioned interpretations. Their research of Finnish educational policies and curricula indicates that, while multicultural education is an overarching theme in the curriculum for the Finnish comprehensive school, and the official documents are generally supportive of the immigrant students' integration process, on a practical level, Finnish students are not required to develop or learn to appreciate a multilingual multicultural society. Holm and Londen (2010) argue that the whole burden of the process of integration is thus placed on immigrant students and no genuine learning, change or adjustment is required of majority students, teachers or schools. Their conclusion thus is that multicultural education in Finland is at least in some ways exclusionary and thus at risk of creating barriers and divisions that will not help integration, but instead solidify the perceived and constructed differences between immigrants and majority students.

These examples indicate that there is at least some degree of consensus among critical educational researchers that the education of immigrant students in the Nordic countries is not currently implemented in a way that promotes equality, justice and social cohesion among citizens in the best possible way. Rather, at least to some extent, education appears to create, strengthen and reify social distinctions, hierarchies and classifications between majority and minority students and thus is at risk of resulting in the unequal treatment of minorities. From the perspective of this article, however, the important question is whether the critique of these educational practices can be justifiably extended to concern liberal theories of citizenship education or, vice versa, when put to practice, these theories can be argued to result in unjust educational policies and practices. In what follows, I attempt to respond to these questions by examining two different branches of liberal theory of citizenship education: 'patriotic' and 'political'.

\section{Liberal theories of citizenship education and 'patriotism'}

Liberal theories of citizenship education are often divided to 'political' and 'comprehensive' approaches, the first being the approach that Rawls (2005, pp. 199-200) associates with his own theory. From the viewpoint of education, the difference between comprehensive and political 
liberalism is that the first presupposes a much more robust approach to citizenship education than the latter, as it demands that students are not only familiarized with a set of public principles, norms, and forms of reasoning, but also that education seeks to inculcate substantive values, such as autonomy (Neufeld, 2013). However, some educational theorists argue that even fostering comprehensive liberal values is not enough to build citizens' faith and attachment to liberal institutions. Accordingly, these authors, including William Galston (1991) and Eamonn Callan (1997), suggest that citizenship education should promote a form of patriotism, which can be defined, following Callan (2002, p. 468), as "an active identification with one's particular nation as a cross-generational political community whose flourishing one prizes and seeks to advance".

To assess the plausibility of this suggestion, it is first important to examine the relation between patriotism and nationalism, because the latter is often associated with the first and sometimes these concepts are even used interchangeably. Let us begin by summarizing what these concepts have in common: patriotism and nationalism share the view that nations do exist and have had a continuous historical existence. Moreover, nationalism and patriotism also agree on the idea that the nation is worthy of one's special attachment to it and action on its behalf (Archard, 1999). Nationalism and patriotism differ, however, in that whereas nationalism claims that a nation should have an independent sovereign statehood and that states are political communities being bound together by a single national identity, patriotism stands for a love of one's country involving a virtuous disposition to act in certain, often self-denying and self-sacrificial ways on behalf of one's country (Archard, 1999; Geller, 1984). Patriotism thus typically stands for a morally preferable, inclusive form of attachment to a political community, while nationalism is often utilized to refer to intolerant and exclusionist forms of identification (Costa, 2009; 2018). Victoria Costa (2018) points out that the difference between patriotism and nationalism can also be drawn on the basis of their different objects, the object of patriotism being an institutionalized political community such as a country, and nationalism's object a group of people who share a certain sense of common identity. However, as Costa (2009) also indicates, the differences between patriotism and nationalism can easily become blurred in practice. At this point, it is perhaps sufficient to say that the form of patriotism promoted by Callan and Galston emphasizes the need of citizens to affectively identify with and become supportive of their political community having a certain type of government, geography, history, culture, and other particularistic features.

Galston's (1991) defense of patriotism is founded on the insight that educational systems have two kinds of goals that are at least to some degree contradictory: on one hand, schools are responsible for fostering student's capabilities of rational inquiry and deliberation. On the other, schools should also produce citizens who are loyal to a particular community. Galston (1991) argues that participation in practices of rational inquiry alone is insufficient for creating attachment to one's political community and the central institutions of the society - in fact, engagement in impartial search for truth might even have corrosive effects on the socially central beliefs that enable such attachment. Hence, Galston suggests that civic education should focus on molding students into good citizens who are willing to support their community and believe in the legitimacy of its social and political arrangements. According to him, this goal is most effectively attained through rhetorical, moralizing history-telling that provides "a pantheon of heroes who confer legitimacy on central institutions and constitute worthy objects of emulation" (Galston, 1991, p. 244). 
Callan (1997) rejects Galston's model of civic education as "sentimental" (p. 106) as he thinks it sustains an unhealthy fiction of moral purity of a specific nation, and thus largely prevents critical revision of the nation's communal past. Moreover, Callan also suggests that the danger in such sentimentalism is that it regards the inherited political present as incapable of improvement, which might result in the legitimation of present injustices. Callan (1997) further points out that the rhetorical inculcation of a glorified national past is in sharp contrast with critical reason and the associated civic virtues upon which the legitimacy of liberal democratic institutions rests. Accordingly, Callan own suggestion is that citizenship education needs to foster both the engagement in one's community and a critical scrutiny of the nation's past. In other words, students should see themselves as both inheritors of a particular tradition and communal past, and capable of critically revising and making the most of their tradition.

It is not difficult to see how the kind of sentimental patriotism Galston promotes might be vulnerable to the critique presented by Säfström and others because, when put to practice, it can easily be transformed into the legitimation of a particular national identity. Furthermore, as Costa (2009) indicates, a deliberative distortion of history for the sake of promoting patriotic feelings might also be harmful for the health and stability of democratic institutions, as it provides inadequate resources for the prevention of a dangerously uncritical support for illegitimate or unjust governments. But is Callan's critical, revisionist patriotism equally vulnerable to these critiques? After all, as Stephen Macedo (2011) points out, patriotism is not necessarily inherently bad or corrupted, as political communities also serve important moral purposes. Namely, it is only via participation in political communities that we can effectively promote just institutions that protect our own and others' equal basic interests. And when a community succeeds in securing legitimacy and treating all its members fairly, that is a great moral achievement, and one that is worthy of the support of the community's members. Accordingly, as Macedo (2011) further points out, participation in such a project is surely a worthy human endeavor.

While it is easy to agree with Macedo on this point, I would nevertheless like to question the necessity of fostering identification with a particular 'patria' in order to attain these desirable features of communal political existence. Evidently, we have good reasons to be specifically concerned with the quality of the particular political community in which we reside. Moreover, it is understandable, and to some extent justifiable, that state-based education teaches a national curriculum rooted in a particular national history and tradition. Therefore, the education of children living, for instance, in Finland teaches them about the history of Finland - the lives of Finnish people, the factors that shaped and made the present Finland, the various constitutive periods, key events and major figures of that history. In other words, it is evident that there needs to be restrictions in terms of the curriculum and that students, regardless of their particular background, benefit from understanding the culture and history of the country in which they live. However, acknowledging the need and benefits of such restrictions does not justify the conclusion that we should foster patriotic identification with, say, Finnish tradition as a common inheritance and project. Such conclusion is deeply problematic for at least two interrelated reasons: first, it assumes that the tradition, project, history, or culture being endorsed is singular. We all have several identities - we are members of nations, but also members of gendered, racial, religious, cultural, economic, and other groups. Our nationality is only one element of a heterogeneous identity, and often our strongest allegiance lies with other dimensions of this identity than our nationality (e.g. Archard, 1999). Moreover, and perhaps more importantly, as Säfström's (2010) critique indicates, our national identity today is multiple 
and fractured, and consists of features that do not arise from one single tradition or collective past. Accordingly, fostering patriotic allegiance to a shared tradition is likely to result in disregard for the equal standing of minorities and incomprehension of their points of view. It is thus in danger of marginalizing these minorities even if the endorsement of a shared tradition involves its critical revision and reinterpretation.

Furthermore, it is also important to point out that an education that privileges a 'patria' as the source of identity and identification and claims that fidelity to it must take precedence over all other forms of commitment, is not only vulnerable to the kind of critique presented by Säfström, but it is also essentially illiberal. As Evan Charney (2003) states, people may be passionate liberal nationalists or patriots, but no liberal state or liberal theory can assume that all persons are such or should be made such. Amy Gutmann (1996) makes a related point in her response to Martha Nussbaum's critique as she emphasizes that democratic citizenship education in the liberal tradition is clearly antithetical to the kind of education that teaches students that they are, above all, citizens of a particular nation state. As Gutmann (1996, p. 69) states,

It is one thing to say that publicly subsidized schooling should teach students the rights and responsibilities of democratic citizenship and quite another to say it should teach them that they are "above all, citizens of the United States." Our primary moral allegiance is not to community [...] our primary moral allegiance is to justice - to doing what is right. Doing what is right cannot be reduced to loyalty to, or identification with, any existing group of human beings.

The reason for providing this rather lengthy citation from Gutmann is that it quite clearly indicates the difference between patriotic and political or "principle-based" (Costa, 2009, p. 98) liberalism: whereas the first stresses the importance of identification with a particular group or community, the latter places emphasis on the ideal of impartiality inherent to morality and justice. Accordingly, as I will argue in the next section, citizenship education drawing from political liberalism is not equally vulnerable to the aforementioned critiques as its patriotic alternative.

\section{Rawlsian political liberalism and citizenship education}

John Rawls' political liberalism was motivated by his recognition of the "fact of reasonable pluralism" (Rawls, 2005, p. xvii) and its implications for contemporary political philosophy. By this "fact", Rawls refers to the diversity of "comprehensive doctrines" (Rawls, 2005, p. xvi) endorsed by reasonable persons in liberal democratic societies - a diversity that would exist even in a fully just society, and which can be eliminated only through the exercise of political oppression. At the heart of Rawls' theory is the idea of a public, political conception of justice on which liberal democratic society's constitution and basic institutions rest. Rawls' own suggestion for such conception is "justice as fairness", which he initially developed in his Theory of Justice (1999), and later in Political Liberalism (2005). According to Rawls, the political conception of justice must be "freestanding" (Rawls, 2005, p. 10, 12-13) with regard to particular comprehensive doctrines. This means that its content should be determined independently of the doctrines affirmed by citizens, and thus it should not favour or discriminate against any particular way of life or view of the good residing in society. Rawls' central claim is that for the political conception of justice to fulfil its purpose, it must be supported by an "overlapping consensus" (Rawls, 2005, p. 144), meaning that it can be accepted by all reasonable citizens from the perspective of their own particular doctrine. Rawls thus characterizes the political conception as a "module" (p. 145) that is compatible with different 
comprehensive doctrines and thus capable of providing mutual terms of cooperation without undermining pluralism.

Importantly, Rawls' political liberalism does not support pluralism without limitations, but it presupposes that all citizens and comprehensive doctrines belonging to the liberal democratic regime are reasonable (Rawls, 2005, p. 49). Rawlsian concept of reasonableness largely rests upon what he refers to as "the criterion of reciprocity" (p. 446, see also 49): that is, the idea that citizens are "prepared to offer one another fair terms of cooperation according to what they consider the most reasonable conception of political justice" (p. 446). These terms should also be such that citizens can expect them to be endorsed by representatives of other reasonable doctrines. Moreover, reasonable citizens are expected to act on these terms - given that other citizens will also do so - even if they conflict with their private interests in some particular situation. Another virtue associated with reasonableness is the "burdens of judgment" (p. 54), referring to citizens' awareness that different, equally reasonable responses can be given to complex ethical and political issues from the standpoints of different reasonable doctrines. Accordingly, reasonable citizens accept a constitutional democratic regime and its companion idea of legitimate law, and they also recognize that when fundamental issues of justice are concerned, they must justify their political claims using public reasons - i.e. reasons that could in principle be accepted by representatives of other reasonable doctrines (Rawls, 2005, p. 453). The concept of reasonableness thus sets the limits to what kind of political claims can be accepted as legitimate within a liberal democratic society consisting of a variety of different, sometimes even incommensurable comprehensive doctrines. The conception of reasonableness thus serves to protect citizens' right to choose their way of life without restraints other than the equal right of other citizens.

As Rawls sees the reasonableness of citizens as a necessary prerequisite for the existence of a stable and just liberal democratic society, the creation of reasonable citizens is a central educational aim in the Rawlsian tradition of educational theory (e.g. Costa, 2011). As I have sought to demonstrate, Säfström and others challenge this liberal, principle-based account of citizenship education by arguing that it relies on a hidden nationalist strategy to mark the boundaries of the political community and to exclude those regarded as non-members from this community. In other words, the critics argue that the liberal principles and virtues (such as reasonableness) presented as 'neutral' are not neutral at all but, rather, derived from a particular way of life and attached to a specific national identity (e.g. Merry, 2018; Säfström, 2010; see also Tamir, 1993). As I indicated in the previous section, in my view, this critique is plausible when directed to the branch of liberal educational theory promoting patriotism. My argument is, however, that it does not apply to Rawlsian citizenship education that builds upon the virtue of reasonableness and aims to remain faithful to the "political" (referring to the "freestanding" condition) nature of Rawls' theory.

It is evidently true that reasonableness is a criterion that marks a democratic community and thus also sets a limit to what kind of doctrines can and cannot be included in this community. However, as the issue of legitimate use of political power is at the core of democracy, establishing a democratic polity always requires setting limits to what kind of political claims can be accepted as legitimate in its midst. Accordingly, every democratic polity is exclusive by nature - this is what Lasse Thomassen $(2006$, p. 452) refers to as the "aporetic" nature of democracy. The difference between democratic and other forms of political exclusion is, however, that the first is not arbitrary in the sense that it would be based on some ideological or nationalist strategy. Rather, democratic exclusion is rationally justifiable. Namely, accepting illiberal, anti-democratic or intolerant political claims as legitimate within democratic processes would mean sacrificing or at least severely jeopardizing the legitimacy of the democratic regime (e.g. Habermas, 1998). For instance, if nationalist, xenophobic or fundamentalist religious 
claims were accepted as legitimate within democratic decision-making, the result would be the gradual degeneration of democratic values of equality, inclusion and tolerance. To prevent this, a democratic polity must establish a minimum threshold of reasonableness concerning the claims that can pass as legitimate in public, political discussion. In this sense, reasonableness as the entry condition of democratic participation - and as an aim of citizenship education serves to protect the right of all citizens to be included regardless of their particular comprehensive doctrine or ethnic and cultural background, as long as they fulfill this condition. Reasonableness is thus also a criterion that cannot be consistently rejected by anyone who wishes not to be oppressed, discriminated against or marginalized by the basic institutions of society. Furthermore, as the notion of reasonableness itself maintains that any policy or practice that elevates one comprehensive doctrine over others or fails to treat equally all reasonable citizens and doctrines belonging to the democratic polity is illegitimate, reasonableness cannot be utilized to marginalize or exclude forms of reasonable otherness without contradicting the very content and purpose of this criterion. Rather, it can be employed to criticize such exclusive and marginalizing educational policies and practices described by Säfström and others.

Another, important question is whether reasonableness provides a sufficient foundation for democratic citizenship education or does sustaining a just and stable democratic polity require a more 'comprehensive' form of citizenship education, as Asger Sørensen argues in his contribution to this volume. Or does the formation of democratic citizens require as much as adherence to a shared 'patria' and tradition, as suggested by Callan (1997) and Galston (1991)? As mentioned above, there is an on-going discussion in the philosophy of education regarding the educational repercussions of Rawlsian political liberalism. Some authors argue that creating sufficient attachment to liberal institutions demands a more robust form of citizenship education than Rawls himself would like to admit (e.g. Callan, 1997; Costa, 2009, 2011). Unfortunately, I cannot go into the details of this discussion in this context. It is perhaps sufficient to say that there might be more than one possible way to satisfy the requirements of political liberalism in terms of pedagogy, curriculum content, and school organization. However, as I have indicated above, I do not think that promoting patriotism should be regarded as one of the. Although Victoria Costa (2009) argues that the status of patriotism in Rawls' theory is not entirely clear or explicit, I claim that the idea of promoting patriotic values in state-run schools is against the overall spirit of Rawls' project in which the requirement of liberal neutrality has a central position.

In my view, citizens' commitment to a shared constitution, and the rules of a common public political culture, primarily require reassurance that society and its basic institutions function in a sufficiently just manner and thus succeed in treating citizens equally. Citizens need sufficient confirmation that they are treated fairly and equally with their fellow citizens by the institutions of the society and that they benefit from being a part of the political community in which they reside. Furthermore, they must also sense that their actions have at least some influence over the way the institutions of their society operate. This reassurance is evidently not easy to establish because the workings of actual institutions are often far from ideal. Accordingly, being acquainted with existing liberal democratic institutions does not guarantee that citizens develop an adherence to these institutions. This is especially true with those citizens who are from the very beginning marginalized and excluded by society's institutions because of their cultural or ethnic identity - not to mention the asylum seekers and refugees who do not even have the status of a citizen, but whose lives are nevertheless influenced by the institutions of the society. The experiences of these people are well described in Kalisha Wills' contribution to this volume. In the next, final section, using Rawlsian theory of citizenship education as my point of departure, my aim is to outline suggestions on how the position of these marginalized groups might be improved in the Nordic educational systems. 


\section{Concluding remarks: liberal citizenship education and the role of immigrant students in the Nordic context}

For a relatively long time, the Nordic educational model was seen as a remarkable exception among the educational systems in Western democracies: it was perceived as being capable of providing equal, high-quality schooling to all citizens regardless of social class, gender or geographic origin, and thus functioning as a crucial instrument for social justice and security (e.g. Lundahl, 2016). However, in recent decades school segregation, and differences in the quality of education between different schools and school districts, have increased rapidly in all Nordic countries. As a consequence of increased possibilities of school choice, and the flight of middle-class students from schools with increasing proportions of immigrant students, schools are becoming more and more differentiated in terms of socio-economic and ethnic factors, which erodes the previous Nordic vision of schools as arenas of social equality. Students with immigrant backgrounds often lack the economic and social resources for making active choices regarding their education and thus they are those suffering the most from these changes in the school system.

In the current situation with immigrant students being in a marginalized position, citizenship education promoting patriotic values is most likely to increase the sense of alienation in immigrant students and thus deepen the gap between them and the majority students. Accordingly, I see patriotism as a counter-productive and, ultimately, philosophically unjustifiable strategy for citizenship education; one, which can be expected to weaken largescale social cohesion and solidarity among citizens rather than strengthen them. The alternative that I have proposed builds upon the Rawlsian notion of reasonableness which, as I have argued, is a criterion that cannot be reasonably rejected by anyone who wants to live in liberal democratic society and maintain the right not to be discriminated against, due to one's background or the comprehensive doctrine one affirms, by society and its institutions. I have also insisted that reasonableness serves to protect the right of all citizens to be included and thus cannot be used in such marginalizing or discriminative ways as suggested my Säfström, at least not without contradicting the content and purpose of the notion.

Accordingly, I suggest that Nordic societies cannot expect immigrants to endorse a given Danish, Swedish, Norwegian or Finnish identity or an inherited tradition; no liberal democratic society can justifiably demand that. What can be justifiably demanded of immigrants and the majority population alike, and what should also be promoted by citizenship education, is reasonableness. However, it is evident that citizens can be expected to be reasonable only to a limited degree if the institutions of the society fail to treat them fairly and provide them equal status as citizens. Hence, from the perspective of immigrant students, one of the most important measures to foster reasonable citizenship in the Nordic countries is to terminate the aforementioned structural changes in the school systems, which have undeniably placed immigrant students in even more vulnerable and unequal position than before. Moreover, the responsibility for making the school an equal setting for all students should be distributed to the curriculum, the school system, individual schools, teachers and the majority students so that the burden of the integration process is no longer placed solely on immigrant students.

In terms of the curriculum, I broadly share Costa's (2009) view that educating students about liberal conceptions of justice, the philosophical arguments that can be provided to support them, and the way they are or should be implemented in the institutions of the society, might be a more direct and justifiable route to inspiring dispositions associated with democratic citizenship than 'patriotic' education. As Costa further points out, demonstrating to students that there are valuable normative ideals, such as conceptions of justice, that are designed to protect the freedom and equality of citizens, and which also justify the design of actual political institutions 
and laws, might encourage students' identification with these institutions, diminish their sense of alienation in the society, and enable them to take a more active role as citizens. Especially in the case of immigrant students, it is important to draw attention to such laws and regulations that protect citizens against discrimination on the basis of religion, culture or ethnic background, as well as the conceptions of justice that can be used to support these laws. Furthermore, while citizenship education should evidently foster students' faith in the institutions of society, it should also make explicit that it is the duty of these institutions to protect all citizens from unequal and unfair treatment, and therefore such institutional policies and practices that violate against commonly held conceptions of justice should not be tolerated. Accordingly, citizenship education should encourage students to take part in normative assessment of one's society and its institutions and it should also familiarize them with relevant ways and channels of political influencing. This should also include discussing the significance and justification of controversial forms of political influencing, such as civil disobedience and conscientious objection.

Moreover, despite the fact that Rawls (2005) himself limits his theory to concern "closed societies" (p.12), in today's globalized world characterized by phenomena such as massmigration and international mobility, citizenship education might benefit from adopting a more cosmopolitan approach than suggested by Rawls. This might include discussing issues of justice in terms of human rights and how these rights ought to be reflected in the constitution, laws and institutions of particular nation states. This kind of 'cosmopolitan' approach, which is discussed in much more detail and depth in this volume by Niclas Ronnström, might be beneficial for diminishing the juxtaposition between immigrant and majority students and especially citizens and non-citizens, the latter including refugees and asylum seekers. It seems that in the current situation with unforeseen number of refugees entering Europe and the Nordic countries, maintaining a stable and just democratic society over time cannot succeed without considering the role and rights of people who do not yet have the status of a citizen, but whose lives are nevertheless significantly influenced by society's institutions, including the school system. 


\section{References}

Archard, D. (1999). Should we teach patriotism? Studies in Philosophy and Education, 18(3), $157-173$

Biesta, G. (2009). Sporadic democracy: education, democracy, and the question of inclusion. In M. Katz, S. Verducci \& G. Biesta (Eds.). Education, democracy and the moral life (pp. 101-112). Dodrecht: Springer

Biesta, G. (2011). The ignorant citizen: Mouffe, Rancière, and the subject of democratic education. Studies in Philosophy and Education, 30(2), 141-153

Callan, E. (1997). Creating citizens: political education and liberal democracy. Oxford: Clarendon Press

Callan, E. (2002). Democratic patriotism and multicultural education. Studies in Philosophy and Education, 21(6), 465-477

Charney, E. (2003). Identity and liberal nationalism. American Political Science Review, 97(2), 295-310

Costa, V. (2009). Justice as fairness, civic identity and patriotic education. Public Affairs Quarterly, 23(2), 95-114

Costa, V. (2011). Rawls, citizenship, and education. New York \& London: Routledge

Costa, V. (2018) Patriotism and nationalism. In P. Smeyers (ed.) International handbook of philosophy of education, vol. II (pp. 1389-1401). Cham: Springer.

Galston, W. (1991). Liberal purposes: goods, virtues, and diversity in the liberal state. Cambridge: Cambridge University Press

Geller, E. (1984). Nations and nationalism. Oxford: Oxford University Press

Gutmann, A. (1996). Democratic citizenship. In J. Cohen \& M. Nussbaum (Eds.). For the love of country? (pp. 66-72). Boston, MA: Beacon Press

Gutmann A. (1999). Democratic education (revised ed.). Princeton: Princeton University Press

Habermas, J. (1998). The inclusion of the other: studies in political theory (Trans. C. Cronin \& P. De Greiff). Cambridge, MA: The MIT Press

Holm, G. \& Londen, M. (2010). The Discourse on multicultural education in Finland: education for whom? Intercultural Education, 21(2), 107-120

Jørgensen, S. L. (2015). The history we need: strategies of citizen formation in the Danish history curriculum. Scandinavian Journal of Educational Research, 59(4), 443-460

Lundahl, L. (2016). Equality, inclusion and marketization of Nordic education: introductory notes. Research in Comparative and International Education, 11(1), 3-12

Macedo, S. (2011). Just patriotism? Philosophy and Social Criticism, 37(4), 413-423

Merry, M. S. (2018). Citizenship, structural inequality and the political elite. On Education. Journal for Research and Debate, 1(1). doi: 10.17899/on_ed.2018.1.1

Neufeld, B. (2013). Political liberalism and citizenship education, Philosophy Compass 8(9), 781-797

Rawls, J. (1999). A Theory of Justice (revised edition). Cambridge, MA: The Belknap Press

Rawls, J. (2005). Political liberalism (expanded ed.). New York \& Chichester: Columbia University Press

Reich, R. (2008). Common schooling and educational choice as a response to pluralism. In W. Feinberg \& C. Lubienski (Eds.). School choice policies and outcomes: philosophical and empirical perspectives (pp. 21-40). Albany, NY: SUNY Press

Säfström, C. A. (2010). The immigrant has no proper name: the disease of consensual democracy within the myth of schooling. Educational Philosophy and Theory, 42(5-6), 606-617

Tamir, Y. (1993). Liberal nationalism. Princeton, NJ: Princeton University Press

Thomassen, L. (2006). The inclusion of the other? Habermas and the paradox of tolerance. Political Theory, 34(4), 439-462 